\title{
Maintaining a global health partnership during the COVID-19 pandemic: a road map from the Toronto Addis Ababa Academic Collaboration in Emergency Medicine
}

\author{
Jennifer M. Bryan ${ }^{1,4}$. Temesgen Beyene ${ }^{2,4}$. Sofia Kebede ${ }^{2,4} \cdot$ Adam Kaufman $^{3,4}$. Tilahun Jiru ${ }^{2,4}$. James Maskalyk ${ }^{1,4}$. \\ Megan Landes ${ }^{3,4}$. Alexandra McKnight ${ }^{4}$. Elayna Fremes ${ }^{4}$ Eileen Cheung ${ }^{3,4}$ on behalf of the Toronto Addis Ababa \\ Academic Collaboration in Emergency Medicine
}

Received: 14 August 2020 / Accepted: 23 December 2020 / Published online: 17 February 2021

(c) The Author(s), under exclusive licence to Canadian Association of Emergency Physicians (CAEP)/ Association Canadienne de Médecine d'Urgence (ACMU) 2021

\begin{abstract}
The Toronto Addis Ababa Academic Collaboration in Emergency Medicine (TAAAC-EM) is an educational global health partnership established 10 years ago to support the growth of EM in Ethiopia. In-person global health partnership activities were disrupted by the COVID-19 pandemic. We describe our five-step process for transitioning our global health partnership to a virtual space. Each step was conducted in collaboration between the University of Toronto and Addis Ababa University EM physicians: (1) risk identification and needs assessment, (2) discussing mitigation strategies, (3) crafting and piloting an approach, (4) revising based on pilot results, 5) implementation with continuous evaluation and revision. Teaching was modified iteratively in response to feedback. Our experience shows that virtual teaching, while not a replacement for in-person engagement, can be a valuable tool both to supplement partnership activities when travel is not possible, and to enhance global health partnerships long term. This approach can also inform the transition of other forms of medical education to the virtual space.
\end{abstract}

Keywords Global health $\cdot$ Postgraduate medical education $\cdot$ Continuing professional development $\cdot$ Pandemic $\cdot$ COVID19. Virtual education

\section{Résumé}

La Toronto Addis-Ababa collaboration universitaire en médecine d'urgence (TAAAC-EM) est un partenariat mondial en éducation à la santé établi il y a 10 ans pour soutenir la croissance de la médecine d'urgence en Éthiopie. Les activités du partenariat mondiale pour la santé en personne ont été perturbées par la pandémie de COVID-19. Nous décrivons notre processus en cinq étapes pour la transition de notre partenariat mondial pour la santé vers un espace virtuel. Chaque étape a été menée en collaboration entre les médecins d'urgences de l'Université de Toronto et de l'Université d'Addis-Ababa : 1) identification des risques et évaluation des besoins, 2) discussion des stratégies d'atténuation, 3) élaboration et pilotage d'une approche, 4) révision basée sur les résultats des projets pilotes, 5) mise en œuvre avec évaluation et révision continues. L'enseignement

Jennifer M. Bryan

Jennifer.Bryan@utoronto.ca

1 Division of Emergency Medicine, Department of Medicine,

University of Toronto, Toronto, ON, Canada

2 Department of Emergency Medicine, College of Health Sciences, Addis Ababa University, Addis Ababa, Ethiopia

3 Division of Emergency Medicine, Department of Family and Community Medicine, University of Toronto, Toronto, ON, Canada

4 Toronto Addis Academic Collaboration in Emergency Medicine (TAAAC-EM), Toronto, ON, Canada 
a été modifié de manière itérative en réponse aux commentaires. Notre expérience montre que l'enseignement virtuel, bien qu'il ne remplace pas l'engagement en personne, peut être un outil précieux à la fois pour compléter les activités de partenariat lorsque les déplacements ne sont pas possibles, et pour renforcer les partenariats mondiaux pour la santé à long terme. Cette approche peut également faire apprendre la transition d'autres formes de formation médicale vers l'espace virtuel.

\section{Background}

The Toronto Addis Ababa Academic Collaboration in Emergency Medicine (TAAAC-EM) was established 10 years ago as an educational partnership between the University of Toronto and Addis Ababa University [1] designed to support the development of a community of emergency medicine (EM) specialists in Ethiopia. Here we discuss the impact of the COVID-19 pandemic on our global health partnership and the innovations that have allowed it to remain effective.

Our partnership is built on a curriculum designed collaboratively by University of Toronto and Addis Ababa University faculty. While Addis Ababa University staff lead key parts of the curriculum, many teaching requirements are met by visiting University of Toronto staff and senior residents during 1-month teaching trips in Addis Ababa three times per year. The COVID-19 pandemic resulted in the first ever cancellations of teaching trips. We needed to quickly identify ways of engaging from a distance. Until now there had been no clear pathway identified in the literature for transitioning an in-person global health education partnership to a virtual space.

\section{Rationale}

The pandemic threatened the solidarity and trust we had built over a decade of collaboration. We were motivated to find strategies for synchronous sessions to maintain the interactive nature of our sessions and promote ongoing relationship building. This led to a rapid pivot to virtual education.

\section{Description of innovation}

Our five-step approach to transitioning to a virtual space was inspired by Deming's cycle of change model [2] and is outlined in Table 1. This was based on a scoping consultation with Addis Ababa University EM colleagues. Each step was conducted through close collaboration between University of Toronto and Addis Ababa University EM physicians.

There have been three continuing professional development sessions (in addition to the pilot sessions discussed in Table 1): one on point of care ultrasound and COVID-19, one on advocacy and hospital administration, and one on bioethics and its application to the pandemic. We also facilitated three wellness sessions for staff.

Once invitations were extended across Ethiopia, attendees from three additional EM sites participated. Based on feedback from Addis Ababa University EM staff, residents will also be invited to most future continuing professional development and wellness sessions, following a grand rounds format.

Postgraduate teaching began 2 weeks after the first pilot continuing professional development session, using a similar format followed by an evaluation. We have held 15 postgraduate teaching sessions. Synchronous attendance varied from 2 to 28 residents (out of a total of 30). The number of recording views ranged from 2 to 54 (median 12) per session. Of 27 responses to post-session evaluations, 56\% reported at least 1 connection interruption, reinforcing the importance of access to both live and recorded sessions. Most responses (94\% not including two missing responses) indicated that residents felt comfortable participating while being recorded. Instructors noted less interactivity than what would be expected in person due in part to limitations in internet connection (not being able to use the microphone or video reliably and relying on the chat function).

The estimated cost of $\$ 10,000$ per trip for two faculty members and one resident was avoided. We incurred a small new expense of $\$ 226$ for a Zoom business account. Instructors were not compensated financially, and all other administrative costs were unchanged; existing internet access routes were utilized so no additional cost were required for internet connection. Funds not spent on teaching trips due to the disruption of the COVID-19 pandemic will be used for future in person teaching and other initiatives.

\section{Discussion}

Global health partnerships can continue to grow despite the COVID-19 pandemic. TAAAC-EM's five step approach to transitioning to virtual education emphasizes iterative improvement to maintain consistency with the needs of staff and residents. This approach can inform the transition of other forms of medical education to the virtual space. Through virtual education we have reaffirmed our commitment to the TAAAC-EM partnership. We recognize, however, that virtual education is limited for hands-on learning and cannot fully replace in person teaching [3]. Our next 
Table 1 Five step approach to transitioning to a virtual space

\begin{tabular}{lll}
\hline 1. Risk identification/needs assessment & Risks: & $\begin{array}{l}\text { Needs: } \\
\text { Continuing professional development (CPD) } \\
\text { Pccess to reliable internet connection }\end{array}$ \\
& $\begin{array}{l}\text { Staff and residents not able to attend due to clinical } \\
\text { duties } \\
\text { Snilateral content development }\end{array}$ \\
& $\begin{array}{l}\text { Privacy concerns with recording } \\
\text { Teacher and learner fatigue }\end{array}$ \\
& Various online platforms considered. Zoom identified by AAU colleagues as most accessible \\
& Regular communication between AAU and UT staff for ongoing revisions \\
2. Discussing mitigation strategies & Sessions recorded with participant notification, posted to YouTube but not searchable publicly \\
& Instructors recruited from AAU, UT and other GHPs \\
& Two CPD pilot sessions developed and delivered on COVID-19 \\
3. Crafting an approach and piloting & Evaluations and informal feedback from AAU EM leads \\
4. Revising based on pilot results & Iterative improvements: Moderators added to facilitate discussion; written notice of recording added; \\
& invitations extended to EM staff across Ethiopia; roster created of AAU EM staff speakers and \\
& speakers from other GHPs \\
5. Implementation, continuous evalua- & Initial 2-month series of CPD, postgraduate and wellness sessions organized \\
tion and revision & Timing and topics decided collaboratively between AAU and UT staff and AAU residents \\
& Evaluations used to guide ongoing improvement \\
& Regular teaching breaks to reduce teacher and learner fatigue
\end{tabular}

$A A U$ Addis Ababa University, $C P D$ continuing professional development, $E M$ emergency medicine, GHP global health partnership, $P G M E$ postgraduate medical education, UT University of Toronto

steps are to explore options for procedure and simulation teaching. Once travel to Ethiopia for teaching is possible again, we will use what we have learned to incorporate virtual teaching where it is most effective, allowing us to maximize the value of teaching trips.

\section{Summary}

In-person teaching trips have been central to the success of TAAAC-EM; the cancellation of the first teaching trips in our history due to the COVID-19 pandemic has inspired us to find new ways to support local training of EM physicians in Ethiopia. We offer our experience as a roadmap to other global health partnerships that have been similarly impacted by COVID-19. While not a replacement for inperson engagement, virtual education can be a valuable tool both to supplement partnership activities when travel is not possible, and to enhance global health partnerships long term.

Acknowledgements The authors wish to thank the emergency medicine residents and staff of Addis Ababa University for their continued commitment to building emergency medicine in Ethiopia. They also wish to thank the emergency medicine physicians of the University of Toronto for their ongoing support of TAAAC-EM. The authors would like to acknowledge that although no project-specific funding was received for this virtual education initiative, the TAAAC-EM partnership has received programmatic funding and support from a number of contributors, including (in alphabetical order): Addis Ababa University, the Department of Family and Community Medicine and Department of Medicine, Faculty of Medicine, University of Toronto; the Donner Family Foundation; Mount Sinai Hospital; St. Michael's Hospital; the University Health Network, and generous private donors.

\section{Compliance with ethical standards}

Conflict of interest The authors declare no conflict of interest.

\section{References}

1. Meshkat N, Teklu S, Hunchak C. Design and Implementation of a postgraduate curriculum to support Ethiopia's first emergency medicine residency training program: The Toronto Addis Ababa Academic Collaboration in Emergency Medicine (TAAAC-EM). BMC Med Educ. 2018;18(1):71.

2. Deming WE. Out of the crisis. Cambridge: MIT Press; 2018.

3. Roe D, Carley S, Sherratt C. Potential and limitations of e-learning in emergency medicine. Emerg Med J. 2010;27(2):100-4. 